\title{
Survival following pulmonary rehabilitation in patients with COPD: the effect of program completion and change in incremental shuttle walking test distance
}

This article was published in the following Dove Press journal:

International Journal of COPD

\section{Linzy Houchen-Wolloff' Johanna EA Williams' \\ Ruth H Green² \\ Gerrit Woltmann² \\ Michael C Steiner ${ }^{1,2}$ \\ Louise Sewell' \\ Michael DL Morgan ${ }^{1,2}$ \\ Sally J Singh'}

'NIHR Leicester Biomedical Research Centre - Respiratory, University Hospitals of Leicester NHS Trust, Glenfield Hospital, Leicester, ${ }^{2}$ Department of Respiratory Medicine, University Hospitals of Leicester NHS Trust, Glenfield Hospital, Leicester, UK

Correspondence: Linzy Houchen-Wolloff Centre for Exercise and Rehabilitation Science (CERS), Leicester Respiratory Biomedical Research Centre Respiratory, University Hospitals of Leicester NHS Trust, Glenfield Hospital, Groby Road, Leicester LE3 9QP, United Kingdom

Tel +4401162502759

Fax +440II6 2583494

Email linzy.houchen@uhl-tr.nhs.uk
Rationale: Pulmonary rehabilitation (PR) in patients with COPD has consistently been shown to produce benefits in exercise capacity, symptoms, and health status. The data surrounding survival following PR are less clear. Our aims were to compare the long-term survival in two cohorts of patients referred for PR; those who successfully completed PR, and a comparator group constructed from patients who either did not complete PR or did not start the program. Additionally, we compared survival between those people who were able to achieve a clinically meaningful improvement in exercise capacity (incremental shuttle walking test) following PR with those who were not.

Methods: A retrospective longitudinal analysis of clinical service outcomes was conducted to compare the long-term survival in "completers" and "non-completers" of rehabilitation at two hospitals within the University Hospitals of Leicester NHS Trust from January 1, 2000 to February 23, 2012. For "completers", we also analyzed survival in those meeting (and not meeting) the desired level of change in the incremental shuttle walking test ( $\geq 50 \mathrm{~m}$ vs $<50 \mathrm{~m}$ ).

Results: We present to you the largest dataset on this topic $(n=1,515)$. Survival data were ascertained for 823 (54.3\%) patients with COPD who had completed a course of PR and for 692 (45.7\%) patients who dropped out. Survival time was significantly greater in "completers" compared to "non-completers" of PR $(p<0.001)$. In addition, PR success $(\geq 50 \mathrm{~m}$ change in walking distance) was also associated with improved survival $(p<0.05)$.

Conclusion: The data show an association between completion of PR and survival. In addition, PR success ( $>50 \mathrm{~m}$ change in walking distance) was also associated with improved survival.

Keywords: survival, COPD, exercise

\section{Introduction}

Globally, 2.75 million deaths are attributed per annum to COPD, making it the third most common cause of death and projected to rise even further. ${ }^{1,2}$ Most therapies for COPD are focused on providing symptomatic relief and managing disease exacerbations rather than prolonging life. ${ }^{3}$

Pulmonary Rehabilitation (PR) has established efficacy in the management of COPD and is recognized as a cornerstone of treatment in international disease management guidelines. ${ }^{4,5}$ The evidence base for PR in patients who consider themselves disabled by their symptoms is centered on its impact on exercise performance and health status. ${ }^{5-7}$ We know that physical activity and exercise capacity influences allcause mortality for patients with $\mathrm{COPD},{ }^{8}$ yet the data surrounding survival following 
PR are less clear. One would presume that because baseline exercise capacity influences survival, ${ }^{9}$ and because PR improves exercise tolerance, ${ }^{5}$ that intuitively PR would improve survival. However, the latest Cochrane systematic review of $\mathrm{PR}$ following an acute-exacerbation ${ }^{10}$ indicated that, when data from small trials are pooled, rehabilitation has no real effect on mortality. However, none of the studies were powered for mortality. Of the six studies included in the review, one showed a positive effect of PR on mortality, ${ }^{11}$ one a negative effect, ${ }^{12}$ and four no effect. ${ }^{13-16}$ In stable patients, one study, from more than 20 years ago ${ }^{17}$ did find a slight, but non-significant difference in survival between an 8-week comprehensive PR group (67\%) and an 8-week education alone group ( $56 \%$ ) at 6 years follow-up ( $p=0.32)$. However, long-term randomized trials where $\mathrm{PR}$ is withheld from a control group are today ethically unacceptable because the benefits of PR are so compelling. ${ }^{5}$ Currently this question can only be addressed indirectly by comparing long-term survival in two cohorts of patients referred to PR; those who successfully complete PR and those who do not complete the program.

In recent times, a few studies have observed survival in patients who have completed rehabilitation. Most recently and reported in this journal, Camillo et $\mathrm{al}^{18}$ have examined the impact of baseline and change in the 6-minute walk distance (6MWD) following rehabilitation on 5-year survival. They were able to show that both low 6MWD at baseline $(<350 \mathrm{~m})$ and a lack of improvement in the 6MWD following rehabilitation ( $<30 \mathrm{~m}$ change) were associated with worse 5 -year survival in 423 patients with COPD. However, this study included those who had completed 3 months of rehabilitation (the effect of non-completion is unknown) and used the 6MWD as the outcome of interest. Previous studies had similarly shown that the 6MWD is a strong predictor of mortality. ${ }^{19-21}$ One study has observed the relationship between survival and exercise tolerance (using the incremental shuttle walking test [ISWT]) prior to rehabilitation. In this study, Ringbaek et al found that the risk of death increased markedly when the ISWT at baseline was $<170$ m (relative risk $=2.84)^{22}$ from data on 416 patients.

To our knowledge, only one previous study has compared the survival rates in patients with COPD who completed PR $(n=116)$ and those who did not complete the program (either dropped out or declined to take part, $n=130$ ). In 2004, Cote and Celli used the BODE (Body mass index [BMI], airflow Obstruction $\left[\mathrm{FEV}_{1}\right]$, Dyspnea [Medical Research Council (MRC) grade] and Exercise capacity [6MWD]) index as a predictor of survival in completers and non-completers of PR.
The BODE index did improve by $19 \%$ in the completed PR group, although returned to baseline by 2 years. It is likely that changes in the 6MWD and/or dyspnea drove this change following PR, although this was not reported. At 2 years they found that respiratory mortality was 7\% in the completed PR group vs 39\% for the no PR group. ${ }^{23}$ However, no previous studies have compared completers and non-completers of PR and used the change in ISWT as the outcome on which to examine survival status. As well as these unique aspects to our study, we report the largest dataset on this topic to date $(n=1,515)$.

Our research question was: is the completion of PR associated with improved survival? Our aims were to compare the long-term survival in two cohorts of patients referred to PR; those who successfully completed PR, and a comparator group constructed from patients who either did not complete PR or did not start the program. Additionally, we compared survival between those people who were able to achieve a clinically meaningful improvement in exercise capacity (ISWT) following PR with those who were not.

\section{Methods}

We conducted a retrospective observational study of longitudinal outcomes on all patients with a confirmed diagnosis of COPD who had been assessed for outpatient-based PR at two hospitals within the University Hospitals of Leicester NHS Trust from January 1, 2000 to February 23, 2012.

\section{Sample}

A total of 1,515 patients had predominately been referred to the PR service by respiratory physicians or GPs in primary care and were largely stable (not post-exacerbation). Participants were included for analysis if they had given their written consent for their data from the PR assessment to be recorded and evaluated for audit purposes. The only exclusion criteria were either no record of written consent or missing data for the unique hospital patient number which would preclude ascertaining mortality status for the individual. The study was considered by the UK National Regional Ethics Service, Leicestershire, Northamptonshire and Rutland Research Ethics Committee to be an evaluation of a clinical service and as such, not requiring ethical approval.

\section{Measures}

All measures and outcomes recorded were part of the clinical care of patients referred to the PR service. Spirometry was performed at baseline according to accepted international standards. ${ }^{24}$ Outcome measures were recorded by a trained 
health care professional at the initial assessment for PR and following completion of the program. Maximal exercise capacity was assessed using the ISWT. ${ }^{25}$ During exercise testing, resting and post-exercise oxygen saturation and heart rate were recorded. The ISWT was performed on at least two occasions at baseline to reduce any learning effect. ${ }^{26}$ Age and gender were recorded together with smoking history, height and weight, self-reported exercise limitation (using the MRC dyspnea scale), and oxygen use. Severity of COPD on spirometric classification was assigned as per the 2007 GOLD guidelines. ${ }^{27}$

The PR program was a 7-week, outpatient-based program where patients attend 2-hour sessions twice a week, aligned with international standards. ${ }^{5}$ The exercise component of the program was predominately centered on endurance-based walking and prescribed at a level equating to $85 \%$ of predicted peak maximal oxygen uptake $\left(\mathrm{VO}_{2}\right)$, calculated using the value for the maximum distance achieved on the ISWT at initial assessment. ${ }^{28}$ Additionally, patients were given a home exercise program to follow which encouraged daily walking. The program also had a strength training component based on American College of Sports Medicine (ACSM) guidelines where patients carried out upper and lower limb strength exercises three times a week using free weights, both at the hospital and at home. ${ }^{29}$ The education program contained advice and information on a range of topics such as medication and inhaler technique, coping with breathlessness and chest clearance, exacerbation management, energy conservation, relaxation skills, and the importance of exercise, and was predominately delivered in an informal lecture-based format with opportunity for questions and discussion to support behavior change. Following completion of the program, patients were advised to continue their walking and strength exercises at home but there were no formal follow-up arrangements.

\section{Mortality status and calculation of length of follow-up}

As our program has been running for many years, some patients had been assessed for PR on more than one occasion. In this event, it was decided to use baseline data relating to the first completed PR episode, termed the index assessment, to calculate length of follow-up. For patients who had been assessed more than once but each time had either dropped out of PR or not started the program at all, we used baseline data relating to the first contact with the PR service to calculate length of follow-up. Mortality status for each identified patient was ascertained by interrogating the hospital database on February 23, 2012. If patients were alive on this date, then the number of days from the date of the index PR assessment to February 23, 2012 was calculated. If patients had died then the number of days from date of the index assessment to date of death was calculated.

\section{Completion of PR and "response" to exercise training}

Patients were classified as having completed a course of PR if they had any data recorded for a post-PR assessment. The dataset was rigorously checked for duplicates to ensure that no patient was classified as both having completed a course of PR and also as a drop out from the program. For those patients who completed PR, we further subdivided people into those who were classified as having successfully "responded" to exercise training ie, they achieved a change in ISWT distance following PR of $50 \mathrm{~m}$ or more (rounded up from the value of the minimal clinically important difference [MCID] of the ISWT $=47.5 \mathrm{~m}$ ) or as a "non-responder" to exercise training if the change in ISWT was $<50 \mathrm{~m}^{30}$

\section{Statistical analysis}

Baseline differences were compared between those patients who completed PR and "non-completers", as well as between "responders" and "non-responders" to exercise training using independent $t$-tests for continuous variables while chi squared tests were used to compare categorical variables. Survival time was compared for "completers" and "non-completers" and "responders" and "non-responders" using Kaplan Meir survival analysis. Differences in survival in both cases were analyzed with the use of the log rank test. Cox regression analysis was used to generate regression beta coefficients (B) for a range of baseline variables (age at assessment as a time dependent variable, $\mathrm{FEV}_{1}[\%$ predicted], BMI, MRC grade, baseline ISWT distance, gender, use of oxygen and pack years smoked) to determine factors that independently predicted survival. The model was run twice, firstly to include the effect of completion of rehabilitation on survival and secondly to include the value of meter change in ISWT for those patients classified as "completers". We calculated the relative reduction of risk of death for each meter change in the ISWT following PR using the value of the exponential of B (Exp B) generated in the Cox regression analysis: $100 \%-(100 \% \times \mathrm{ExpB})$. Continuous variables are presented as mean (SD) unless otherwise stated. A $p$-value of less than 0.05 was considered to be statistically significant in all analyses. Analysis was carried out using Predictive Analytics Software (PASW) 
Statistics version 18 (formerly SPSS [IBM Corporation, Armonk, NY, USA]).

\section{Results}

Mortality status was ascertained for 1,515 patients with a confirmed diagnosis of COPD who had been assessed for PR at our institution from the beginning of January 2000 to February 2012 and fulfilled the inclusion/exclusion criteria. Table 1 presents demographic data and baseline measures for all patients at the time of the index assessment. Patients were predominately male, with $\mathrm{FEV}_{1} \%$ predicted of $<50 \%$ and MRC grades 3/4. An assessment on completion of a course of PR was ascertained for 823 (54.3\%) of the patients in the cohort while data were available for 692 (45.7\%) patients who did not start or dropped out of rehabilitation and did not go on to complete a further course of PR.

Table 2 shows a comparison of the variables at the index assessment between those patients who completed a full course of PR and those who did not start or dropped out. Patients who did not complete PR were found to be more disabled than "completers", with a statistically significantly worse MRC dyspnea score (median 3 vs 4, $p<0.001$ ), lower BMI (26.53 vs 27.30, $p=0.024)$, and a lower baseline ISWT

Table I Patient demographics at baseline pulmonary rehabilitation assessment

\begin{tabular}{|c|c|}
\hline Mean (SD) unless otherwise stated & $n=I, 5 \mid 5$ \\
\hline Age at assessment (years) & $69.10(9.10)$ \\
\hline Gender \% (male/female) & $60 \% / 40 \%$ \\
\hline $\mathrm{FEV}_{1}(\mathrm{~L})$ & I. $14(0.53)$ \\
\hline$\%$ predicted $\mathrm{FEV}_{\text {, }}$ & $47.25(2 \mid .5 I)$ \\
\hline $\mathrm{FVC}(\mathrm{L})$ & $2.4 I(2.92)$ \\
\hline Home oxygen use, total (n) & 228 \\
\hline PRN (n) & 112 \\
\hline LTOT (n) & 116 \\
\hline BMI $\left(\mathrm{kg} / \mathrm{m}^{2}\right)$ & $26.96(6.13)$ \\
\hline MRC dyspnea grade & $3.5 \mathrm{I}(1.04)$ \\
\hline Grade $2(\%)^{\#}$ & 16.7 \\
\hline Grade 3 (\%) $)^{\#}$ & 26.0 \\
\hline Grade 4 (\%) ${ }^{\#}$ & 25.6 \\
\hline Grade $5(\%)^{\#}$ & 17.6 \\
\hline Pack years smoked & $43.92(26.5 \mathrm{I})$ \\
\hline ISWT distance (meters) & $199.40(134.99)$ \\
\hline GOLD stage I (\%) & 0.1 \\
\hline GOLD stage II (\%)\# & 3.8 \\
\hline GOLD stage III (\%) & 24.5 \\
\hline GOLD stage IV (\%) ${ }^{\#}$ & 53.3 \\
\hline
\end{tabular}

Notes: "Percentages do not add up to $100 \%$; $18.2 \%$ of patients could not be classified into GOLD stage due to missing data for either FEV , FVC, age or height; 14.1\% missing data for MRC grade.

Abbreviations: PRN, pro re nata (as and when); LTOT, long-term oxygen therapy; BMI, body mass index; MRC, Medical Research Council; ISWT, incremental shuttle walking test; GOLD, Global initiative for chronic Lung Disease. distance ( $179 \mathrm{~m}$ vs $216 \mathrm{~m}, p<0.001)$. They were also found to be younger ( 68.39 vs 69.70 years) which was statistically significant $(p=0.005)$.

Figure 1 presents the Kaplan Meir survival analysis for completers and non-completers of PR. A statistically significant difference was found between the two groups (log rank test, $p<0.001)$. Of the 823 patients who completed rehabilitation, a change of $\geq 50 \mathrm{~m}$ in the ISWT was found in $53 \%(n=437)$ of the patients, classified as successful "responders" to exercise training. Figure 2 presents the survival analysis between the responders and non-responders to exercise training and a statistically significant difference in survival time was found between the groups (log rank test, $p<0.001$ ).

Cox regression was used to determine which factors independently predicted survival. Factors used in the model were age at time of assessment (as a time dependent variable), pack years smoked, gender, MRC grade, BMI, FEV $\%$ predicted, home oxygen use, and completion of PR (Table 3). Completion of rehabilitation was found to be a significant and independent predictor of survival $(p<0.001)$. Other factors found to independently predict survival were higher baseline ISWT distance $(p<0.001)$, younger age at assessment $(p<0.001)$, lower (ie, better) MRC dyspnea grade $(p=0.003)$, higher BMI $(p<0.036)$, and not using home oxygen $(p=0.034)$. However, severity of FEV $1(\%$ predicted), number of pack years smoked or gender did not independently predict survival.

For those people who completed PR, a second Cox regression model was run using the same factors as described previously, but substituting magnitude of change in ISWT distance instead of completion of PR in the model (Table 4). A larger magnitude of change in ISWT was found to significantly predict survival $(p=0.018)$ as did higher baseline ISWT distance $(p<0.001)$ and higher BMI $(p<0.001)$, younger age at assessment $(p=0.003)$, and higher $\mathrm{FEV}_{1}(\%$ predicted $)$ ( $p=0.026$ ). Using the value of the Exp B for magnitude of change in ISWT: Exp B =0.996 (CI 0.994 to 0.998) we calculated that the relative risk of dying was reduced by $0.4 \%$ for every meter improvement in the ISWT following PR: $100 \%-(100 \% \times 0.996)$, with calculations corrected for age as a time dependent variable, BMI, MRC grade, baseline ISWT, and $\mathrm{FEV}_{1} \%$ predicted. This is more meaningful if the value of change in ISWT Exp B is raised to the power $\left({ }^{\wedge}\right)$ equal to the magnitude of improvement in ISWT. For example, if a patient improved by $100 \mathrm{~m}$ following PR, then the risk of death would be $33 \%$ lower $(100 \%-[100 \% \times$ $\left.\left.\left[0.996^{\wedge} 100\right]\right]=33\right)$. 
Table 2 Baseline variables for those patients who completed and did not complete pulmonary rehabilitation

\begin{tabular}{|c|c|c|c|}
\hline $\begin{array}{l}\text { Baseline mean (SD) } \\
\text { unless otherwise stated }\end{array}$ & $\begin{array}{l}\text { Completed PR } \\
n=823 \text { (54.3\%) }\end{array}$ & $\begin{array}{l}\text { Did not complete PR } \\
n=692(45.7 \%)\end{array}$ & $p$-value \\
\hline Age at assessment (years) & $69.70(8.57)$ & $68.39(9.65)$ & $0.05 *$ \\
\hline Men, $\mathrm{n}(\%)$ & 495 (60.15\%) & $414(59.83 \%)$ & NS \\
\hline Women, n (\%) & 328 (39.85\%) & $278(40.17 \%)$ & NS \\
\hline $\mathrm{FEV}_{1}(\mathrm{~L})$ & $\mathrm{I} .14(0.53)$ & $1.14(0.52)$ & NS \\
\hline$\%$ predicted $\mathrm{FEV}$ & $47.06(22.35)$ & 47.40 (20.79) & NS \\
\hline Home oxygen use, n (\%) & II 5 (I3.97\%) & 113 (16.33\%) & NS \\
\hline BMI $\left(\mathrm{kg} / \mathrm{m}^{2}\right)$ & $27.30(6.19)$ & $26.53(6.03)$ & NS \\
\hline MRC grade median (IQR) & $4.0(1)$ & $3.0(1)$ & $<0.00 I^{*}$ \\
\hline ISWT (meters) & $216.28(|28.9|)$ & $179.30(139.35)$ & $<0.001 * *$ \\
\hline
\end{tabular}

Notes: *Significant at $p<0.05 ; * *$ significant at $p<0.00$ I.

Abbreviations: PR, pulmonary rehabilitation; BMI, body mass index; MRC, Medical Research Council; IQR, interquartile range; ISWT, incremental shuttle walking test; NS, not significant.

\section{Discussion}

This study supports the idea that patients with COPD who successfully complete a course of PR have a statistically significant survival advantage compared with those patients who dropped out of the program or failed to start in the first place. Previous studies have shown that exercise tolerance (either measured by the 6MWD test or the ISWT) is an independent predictor of mortality in the COPD population. ${ }^{22,23}$ Arguably therefore you might expect that by increasing exercise tolerance, you can improve survival.

This is the first study to examine survival for both "completers" and "non-completers" of PR and use the change in the ISWT as the exercise measure of interest. Additionally,

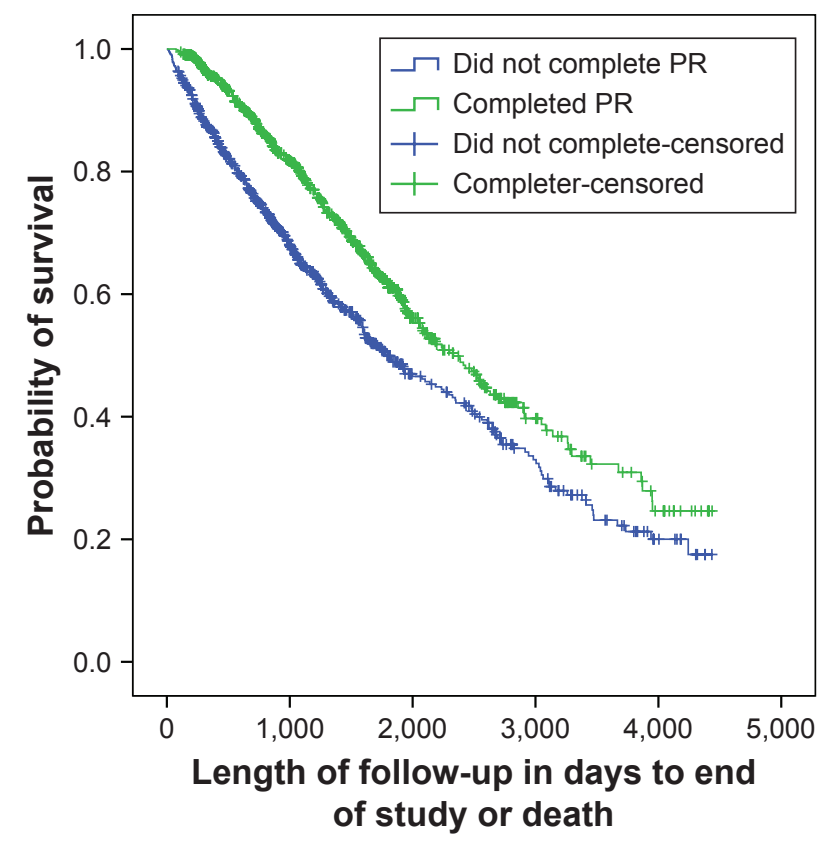

Figure I Kaplan Meir survival analysis for "completers" and "non-completers" of PR. Note: Significant at $p<0.00$ I, log rank test.

Abbreviation: PR, pulmonary rehabilitation. we have presented the largest dataset to date on this topic $(n=1,515)$. In our study we have found that the magnitude of change in exercise tolerance following rehabilitation predicted survival, even when the analysis was adjusted for other variables of mortality. We found that for every meter improvement in distance walked on the ISWT, the relative risk of mortality was reduced by $0.4 \%$. Using the cut-off value for the MCID of the ISWT, if a patient improved by $50 \mathrm{~m}$ then the risk of death would be $(100 \%-[100 \% \times[0.996$ $\left.\left.\left.{ }^{\wedge} 100\right]\right]=33\right)=17.6 \%$ lower. This result was also independent of the baseline value of the ISWT.

Previous studies have shown that PR is beneficial in approximately $70 \%$ of patients in terms of exercise tolerance

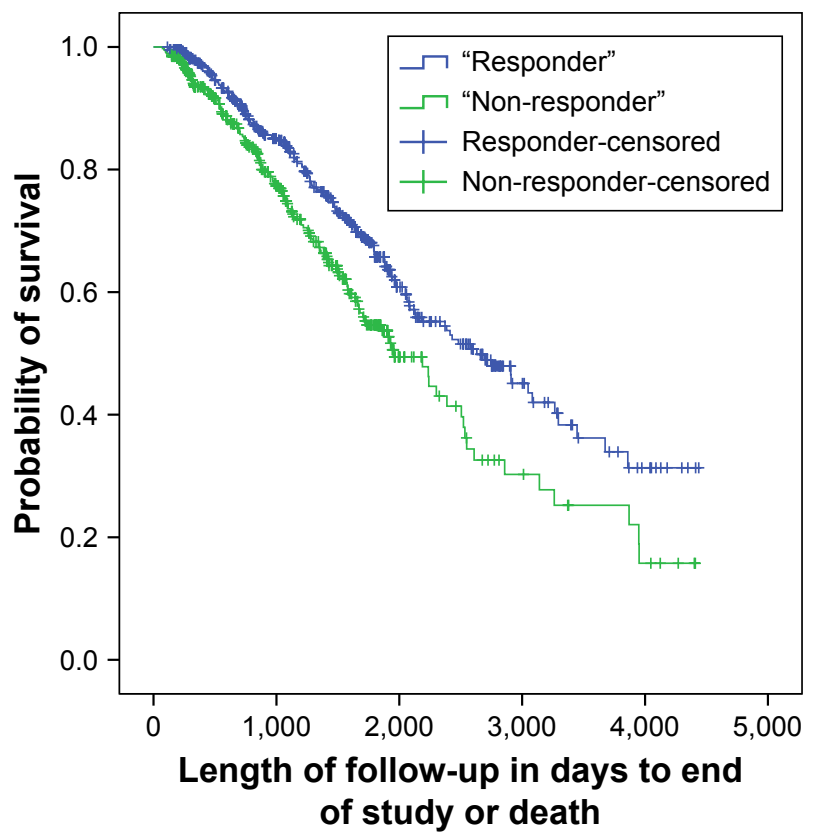

Figure 2 Kaplan Meir survival analysis for "responders" and "non-responders" in exercise training.

Note: Significant at $p<0.00$ I, log rank test. 
Table 3 Results of Cox regression analysis to identify factors that independently predict mortality, including completion of a pulmonary rehabilitation program

\begin{tabular}{llll}
\hline & B & $\begin{array}{l}\text { Exponential } \\
(95 \% \text { CI) for B }\end{array}$ & -value \\
\hline Age at assessment ${ }^{\#}$ & $<0.00 I$ & $1.000(1.00)$ & $<0.00 I^{* *}$ \\
Pack years smoked & 0.002 & $1.002(0.909-1.007)$ & 0.346 \\
Gender & 0.237 & $1.267(0.998-1.609)$ & 0.052 \\
MRC grade (pre-PR) & 0.193 & $1.213(1.066-1.38 I)$ & $0.003^{*}$ \\
BMI & -0.023 & $0.977(0.957-0.999)$ & $0.036^{*}$ \\
ISWT (pre-PR) & -0.003 & $0.997(0.996-0.998)$ & $<0.00 I^{* *}$ \\
\% predicted FEV & -0.010 & $0.990(0.979-1.002)$ & 0.103 \\
Home oxygen use & -0.303 & $0.738(0.558-0.978)$ & $0.034^{*}$ \\
Completion of PR & 0.455 & $1.560(1.238-1.967)$ & $<0.00 I^{* *}$ \\
\hline
\end{tabular}

Note: ${ }^{\# A g e}$ at assessment as a time dependent covariable, *significant at $p<0.05$, **significant at $p<0.001$.

Abbreviations: MRC, Medical Research Council; PR, pulmonary rehabilitation; BMI, body mass index; ISWT, incremental shuttle walking test.

and/or quality of life. ${ }^{6,31}$ In our study, $53 \%$ of people improved their exercise tolerance by at least $50 \mathrm{~m}$, rounded up from the MCID of the ISWT $(47.5 \mathrm{~m}) .{ }^{30}$ We found that there was a significant difference in survival between those patients who improved by the MCID (or greater) and those who did not. This may be a healthy survivor effect. It has been acknowledged that the magnitude of response to rehabilitation is highly variable with some patients showing little or no benefit at all to exercise training. ${ }^{32-34}$ This phenomenon is also true in the healthy population and could be linked to genetic factors. ${ }^{35}$ The lack of response may also be down to influences such as poor motivation and compliance or not being able to tolerate a sufficiently intense program as to see a training effect ("failure to intervene"). We were unable to

Table 4 Results of Cox regression analysis to identify factors that independently predict mortality, including magnitude of change in exercise capacity $(\Delta \mathrm{ISWT})$, for patients who completed pulmonary rehabilitation

\begin{tabular}{|c|c|c|c|}
\hline & B & $\begin{array}{l}\text { Exponential } \\
(95 \% \mathrm{CI}) \text { for B }\end{array}$ & $p$-value \\
\hline Age at assessment ${ }^{\#}$ & $<0.001$ & $1.000(1.000)$ & $0.003 * *$ \\
\hline Pack years smoked & 0.002 & $1.002(0.996-1.009)$ & 0.473 \\
\hline Gender & 0.186 & I.204 (0.866-I.673) & 0.269 \\
\hline MRC grade (pre-PR) & 0.164 & I.I $78(0.980-1.416)$ & 0.081 \\
\hline $\mathrm{BMI}$ & -0.065 & $0.937(0.907-0.968)$ & $<0.00 I^{* *}$ \\
\hline ISWT (pre-PR) & -0.003 & $0.997(0.995-0.998)$ & $<0.001 * *$ \\
\hline$\%$ predicted $\mathrm{FEV}$ & -0.021 & $0.979(0.961-0.997)$ & $0.026^{*}$ \\
\hline Home oxygen use & -0.014 & $0.986(0.658-1.476)$ & 0.944 \\
\hline$\Delta \mathrm{ISWT}$ (pre- to post-PR) & -0.003 & $0.996(0.994-0.998)$ & $0.018^{*}$ \\
\hline
\end{tabular}

Note: ${ }^{\#}$ Age at assessment as a time dependent covariable, *significant at $p<0.05$, **significant at $p<0.00 \mathrm{I}$.

Abbreviations: MRC, Medical Research Council; PR, pulmonary rehabilitation; BMI, body mass index; ISWT, incremental shuttle walking test. assess whether or not the workload was the same in the two groups during PR, although exercise prescription was the same. It may be that patients who failed to improve on an exercise test, could have improved on another measure (eg, health status). In our analysis we decided to use an exercise test as our measure of response as we had the most complete data in this category. Importantly, there were no baseline differences between the "responders" and "non-responders" for the outcomes shown in Table 2 (ie, age, gender, MRC grade, $\mathrm{FEV}_{1}$ ).

In line with the most recent ACSM internationally recognized recommendations for physical activity and exercise for older adults, one of the key aims of PR is to support patients to adopt a healthier and more active lifestyle that will enable them to better manage their disease and improve their quality of life. ${ }^{29,36} \mathrm{PR}$ has been proven to be effective in improving health-related quality of life, psychological morbidity, exercise capacity and fitness as well as a reduction in breathlessness. ${ }^{6,31,37}$ Changes in physical activity following rehabilitation are more heterogeneous ${ }^{38}$ and recognizes the fact that improvements in exercise tolerance are not necessarily translated into changes in physical activity, ${ }^{39}$ where a behavior change component is necessary. It is likely that an increase in exercise capacity and/or physical activity following PR may play a part in the mechanism of improving survival and that the level of response to exercise training also appears to be a positive prognostic factor for those able to achieve clinically meaningful gains in exercise capacity. We also found successful completion and magnitude of change in ISWT following PR to be a better predictor of prognosis than $\mathrm{FEV}_{1}$.

\section{Limitations}

There are some limitations in the interpretation of our data. Detailed information regarding reason for drop out, number of PR sessions attended, number and type of comorbidities, number and duration of exacerbations were not available so it is possible that these factors were confounders. In addition, we were unable to ascertain the cause of death from our hospital database interrogation. This information may have been interesting; particularly to differentiate between respiratory and non-respiratory causes of death. The levels of physical activity or maintenance exercise performed in the follow-up period were not recorded. Previously, maintenance rehabilitation has been shown to have little or no effect on survival. ${ }^{40} \mathrm{We}$ did find significant baseline differences between the patients who completed rehabilitation and those who dropped out, with patients who dropped out rating themselves as being 
more disabled by their breathlessness as classified by the MRC dyspnea scale and had a lower mean baseline ISWT value. They were also found to be slightly younger than the "completers" which was statistically, but probably not clinically, significant. These baseline differences may influence the results. However, factors such as gender, BMI, and lung function were not different between the groups. There was also no significant difference in the number of patients on home oxygen (a commonly used clinical marker of disease severity) between the groups (chi square, $p=0.201$ ). This study is an observation of outcomes of clinical practice. We have constructed two comparative groups; one made up of people who, for whatever reason, failed to complete PR (or did not even start on the program) but for whom we had good quality baseline data at a known time point and the other made up of people who had completed at least one course of PR. We have made strenuous efforts to verify the data for any duplication to ensure that the two groups that were compared were unique. The first complete episode was chosen as the index episode over any subsequent episodes as it was felt that this was likely to be when rehabilitation would have had the greatest impact. Important to note is that the survival of someone assessed in 2000 may be different to those assessed in 2012 due to advances in the field, differing assessment processes and changes in treatment, eg, It is also acknowledged that we have "missed" a group of patients; those who were unwilling to even be referred for rehabilitation. Survival in these patients is unknown due to study selection bias.

\section{Conclusion and implications}

These data suggest that there is an association between the successful completion of PR and survival in patients with COPD. In addition, PR success ( $>50 \mathrm{~m}$ change in walking distance) was also associated with improved survival. There are two possible explanations for this. First, the response is as a consequence of the rehabilitation itself, ie, an improvement in general health following rehabilitation is protective. Or, second, this could indicate more positive health behaviors (such as improved physical activity, increased medication adherence, exacerbation recognition), which may have a mediating effect on prognosis. ${ }^{5}$ Although there are still many unanswered questions for referrers to PR, we would suggest that more attention is given to upscale referral rates to PR. Rehabilitation professionals might also like to focus on the "non-completers", who were a more disabled group as well as the "non-responders" as again, this may have an impact on their survival and alternative modes of rehabilitation may be more appropriate for this group of patients.

\section{Acknowledgment}

The research was supported by the NIHR Leicester Biomedical Research Centre - Respiratory. The views expressed are those of the authors and not necessarily those of the NHS, the NIHR or Department of Health.

\section{Disclosure}

The authors report no conflicts of interest in this work.

\section{References}

1. Bloom DE, Cafiero ET, Jané-Llopis E. The global economic burden of non-communicable diseases: a report by the World Economic Forum and the Harvard school of Public Health; 2011. Geneva: World Economic Forum; 2011. Available from: https:/www.weforum.org/reports/ global-economic-burden-non-communicable-diseases. Accessed October 23, 2017.

2. Lozano R, Naghavi M, Foreman K, et al. Global and regional mortality from 235 causes of death for 20 age groups in 1990 and 2010: a systematic analysis for the Global Burden of Disease Study 2010. Lancet. 2012;380(9859):2095-2128.

3. Calverley PM, Anderson JA, Celli B, et al. Salmeterol and fluticasone propionate and survival in chronic obstructive pulmonary disease. N Engl J Med. 2007;356(8):775-789.

4. nice.org.uk [homepage on the Internet]. Chronic obstructive pulmonary disease in over 16s: diagnosis and management. National Institute for Health and Care Excellence; 2010. Available from: http://guidance. nice.org.uk/cG101. Accessed October 23, 2017.

5. Spruit MA, Singh SJ, Garvey C, et al. An official American Thoracic Society/European Respiratory Society statement: key concepts and advances in pulmonary rehabilitation. Am J Respir Crit Care Med. 2013;188(8):e13-e64.

6. Troosters T, Casaburi R, Gosselink R, Decramer M. Pulmonary rehabilitation in chronic obstructive pulmonary disease. Am J Respir Crit Care Med. 2005;172(1):19-38.

7. McCarthy B, Casey D, Devane D, Murphy K, Murphy E, Lacasse Y. Pulmonary rehabilitation for chronic obstructive pulmonary disease. Cochrane Database Syst Rev. 2015;(2):CD003793.

8. Waschki B, Kirsten A, Holz O, Müller KC, Meyer T, Watz H, Magnussen $\mathrm{H}$. Physical activity is the strongest predictor of all-cause mortality in patients with COPD: a prospective cohort study. Chest. 2011;140(2):331-342.

9. Celli BR, Cote CG, Marin JM, et al. The body-mass index, airflow obstruction, dyspnea, and exercise capacity index in chronic obstructive pulmonary disease. N Engl J Med. 2004;350(10):1005-1012.

10. Puhan MA, Gimeno-Santos E, Cates CJ, Troosters T. Pulmonary rehabilitation following exacerbations of chronic obstructive pulmonary disease. Cochrane Database Syst Rev. 2016;12:CD005305.

11. Troosters T, Gosselink R, De Paepe K, Decramer M. Pulmonary rehabilitation improves survival in COPD patients with a recent severe acute exacerbation. [abstract]. Am J Respir Crit Care Med. 2002; 165:A16.

12. Greening NJ, Williams JE, Hussain SF, et al. An early rehabilitation intervention to enhance recovery during hospital admission for an exacerbation of chronic respiratory disease: randomised controlled trial. BMJ. 2014;349:g4315.

13. Behnke M, Taube C, Kirsten D, Lehnigk B, Jorres RA, Magnussen H. Home-based exercise is capable of preserving hospital-based improvements in severe chronic obstructive pulmonary disease. Respir Med. 2000;94(12):1184-1191.

14. Ko FW, Dai DL, Ngai J, et al. Effect of early pulmonary rehabilitation on health care utilization and health status in patients hospitalized with acute exacerbations of COPD. Respirology. 2011;16(4): 617-624. 
15. Ko FW, Cheung NK, Rainer TH, Lum C, Wong I, Hui DS. Comprehensive care programme for patients with chronic obstructive pulmonary disease: a randomised controlled trial. Thorax. 2017;72(2): $122-128$.

16. Man WD, Polkey MI, Donaldson N, Gray BJ, Moxham J. Community pulmonary rehabilitation after hospitalisation for acute exacerbations of chronic obstructive pulmonary disease: randomised controlled study. BMJ. 2004;329(7476):1209.

17. Ries AL, Kaplan RM, Limberg TM, Prewitt LM. Effects of pulmonary rehabilitation on physiologic and psychosocial outcomes in patients with chronic obstructive pulmonary disease. Ann Intern Med. 1995; 122(11):823-832.

18. Camillo CA, Langer D, Osadnik CR, et al. Survival after pulmonary rehabilitation in patients with COPD: impact of functional exercise capacity and its changes. Int J Chron Obstruct Pulmon Dis. 2016;11: 2671-2679.

19. Bowen JB, Votto JJ, Thrall RS, Haggerty MC, Stockdale-Woolley R, Bandyopadhyay T, ZuWallack RL. Functional status and survival following pulmonary rehabilitation. Chest. 2000;118(3):697-703.

20. Pinto-Plata VM, Cote C, Cabral H, Taylor J, Celli BR. The 6-min walk distance: change over time and value as a predictor of survival in severe COPD. Eur Respir J. 2004;23(1):28-33.

21. Enfield K, Gammon S, Floyd J, et al. Six-minute walk distance in patients with severe end-stage COPD: association with survival after inpatient pulmonary rehabilitation. J Cardiopulm Rehabil Prev. 2010; 30(3):195-202.

22. Ringbaek T, Martinez G, Brondum E, Thogersen J, Morgan M, Lange P. Shuttle walking test as predictor of survival in chronic obstructive pulmonary disease patients enrolled in a rehabilitation program. $J$ Cardiopulm Rehabil Prev. 2010;30(6):409-414.

23. Cote CG, Celli BR. Pulmonary rehabilitation and the BODE index in COPD. Eur Respir J. 2005;26(4):630-636.

24. Qaseem A, Wilt TJ, Weinberger SE, et al. Diagnosis and management of stable chronic obstructive pulmonary disease: a clinical practice guideline update from the American College of Physicians, American College of Chest Physicians, American Thoracic Society, and European Respiratory Society. Ann Intern Med. 2011;155(3):179-191.

25. Singh SJ, Morgan MD, Scott S, Walters D, Hardman AE. Development of a shuttle walking test of disability in patients with chronic airways obstruction. Thorax. 1992;47(12):1019-1024.

26. Holland AE, Spruit MA, Troosters T, et al. An official European Respiratory Society/American Thoracic Society technical standard: field walking tests in chronic respiratory disease. Eur Respir J. 2014; 44(6):1428-1446.
27. Rabe KF, Hurd S, Anzueto A, et al. Global strategy for the diagnosis, management, and prevention of chronic obstructive pulmonary disease: GOLD executive summary. Am J Respir Crit Care Med. 2007;176(6): $532-555$.

28. Revill SM, Morgan MD, Singh SJ, Williams J, Hardman AE. The endurance shuttle walk: a new field test for the assessment of endurance capacity in chronic obstructive pulmonary disease. Thorax. 1999;54(3): 213-222.

29. Nelson ME, Rejeski WJ, Blair SN, et al. Physical activity and public health in older adults: recommendation from the American College of Sports Medicine and the American Heart Association. Circulation. 2007; 116(9):1094-1105

30. Singh SJ, Jones PW, Evans R, Morgan MD. Minimum clinically important improvement for the incremental shuttle walking test. Thorax. 2008;63(9):775-777.

31. Scott AS, Baltzan MA, Fox J, Wolkove N. Success in pulmonary rehabilitation in patients with chronic obstructive pulmonary disease. Can Respir J. 2010;17(5):219-223.

32. Laveneziana P, Palange P; ERS Research Seminar Faculty. Physical activity, nutritional status and systemic inflammation in COPD. Eur Respir J. 2012;40(3):522-529.

33. Rodriguez DA, Kalko S, Puig-Vilanova E, et al. Muscle and blood redox status after exercise training in severe COPD. Free Radic Biol Med. 2012;52(1):88-94.

34. Keller P, Vollaard NB, Gustafsson T, et al. A transcriptional map of the impact of endurance training on skeletal muscle phenotype. $\mathrm{J} \mathrm{Appl}$ Physiol (1985). 2011;110(1):46-59.

35. Bouchard C. Genomic predictors of trainability. Exp Physiol. 2012;97(3): 347-352.

36. Nici L, Raskin J, Rochester CL, et al. Pulmonary rehabilitation: what we know and what we need to know. J Cardiopulm Rehabil Prev. 2009;29(3):141-151.

37. Harrison SL, Greening NJ, Williams JE, Morgan MD, Steiner MC, Singh SJ. Have we underestimated the efficacy of pulmonary rehabilitation in improving mood? Respir Med. 2012;106(6):838-844.

38. Cindy Ng LW, Mackney J, Jenkins S, Hill K. Does exercise training change physical activity in people with COPD? A systematic review and meta-analysis. Chron Respir Dis. 2012;9(1):17-26.

39. Singh S. Physical activity and pulmonary rehabilitation - A competing agenda? Chron Respir Dis. 2014;11(4):187-189.

40. Hjalmarsen A, Brenn T, Jongsma Risberg M, Meisler Antonsen K, Kristiansen Benum E, Aaseboe U. Retrospective survival in elderly COPD patients receiving pulmonary rehabilitation; a study including maintenance rehabilitation. BMC Res Notes. 2014;7:210.
International Journal of COPD

\section{Publish your work in this journal}

The International Journal of COPD is an international, peer-reviewed journal of therapeutics and pharmacology focusing on concise rapid reporting of clinical studies and reviews in COPD. Special focus is given to the pathophysiological processes underlying the disease, intervention programs, patient focused education, and self management protocols.

\section{Dovepress}

This journal is indexed on PubMed Central, MedLine and CAS. The manuscript management system is completely online and includes a very quick and fair peer-review system, which is all easy to use. Visit http://www.dovepress.com/testimonials.php to read real quotes from published authors. 